\title{
Options, Challenges and Potentials of Poultry Meat: An Empirical Investigation on European Consumers
}

http://dx.doi.org/10.1590/1516-635x1604431-436

\section{-Author(s)}

Vukasović $T^{\top}$

International School for Social and Business Studies, Mariborska cesta 7, SI - 3000 Celje, Slovenia

\section{Mail Address}

Corresponding author e-mail address University of Primorska Faculty of Mathematics, Natural Sciences and Information Technologies Glagoljaška 8 SI-6000 Koper - Slovenia

DOBA Faculty, Prešernova 1, SI - 2000

Maribor - Slovenia

E-mail: tina.vukasovic@mfdps.si

\section{-Keywords}

Poultry meat, consumer behaviour, EU.

\section{ABSTRACT}

Agricultural market developments have attracted considerable attention recently, due to increasing consumer food prices and sharp short term price fluctuations of agricultural commodity prices. This medium term outlook provides a projection for major EU agricultural commodity markets and agricultural income until the year 2022, based on a set of coherent assumptions. Under these assumptions, agricultural commodity prices are expected to stay firm over the medium term, supported by factors such as the growth in global food demand, the development of the biofuel sector and a prolongation of the long-term decline in food crop productivity growth. EU commodity markets are projected to remain balanced on average over the outlook period, without the need for market intervention. Prospects for agricultural income grow at EU level during the outlook period, resulting from continuing decline in labor input rather than from income increases at sector level (European Commission, 2012). The article concentrates on the prospects for European meat market trends and on results of the primary quantitative research which was carried out in four countries EU member state.

\section{INTRODUCTION}

\section{General meat market prospects}

The EU market is likely to be affected by the on-going economic downturn and historically high levels of unemployment, which tend to push EU demand towards cheaper meat options. The new animal welfare requirements in the pig sector are also expected to play an important role in the near future. As a consequence, total EU meat production, after having increased during both 2010 and 2011, will contract by $2 \%$ over the next two years. After this reduction, total meat production is projected to steadily recover over the ten year horizon and to reach almost 45 million tons in 2022, approximately the same level recorded in 2011. Meat production is mainly driven by increasing poultry and pork meat consumption, as well as by a firm external demand and higher prices. On a per capita basis, EU meat consumption in 2022, at $82.6 \mathrm{~kg}$, would be at approximately the same level as it was in 2009 and 1\% lower than in 2011, despite the improved macroeconomic prospects. Although the average per capita consumption would be higher in the EU-15 than in the EU-N12 (85 $\mathrm{kg} /$ capita versus $73 \mathrm{~kg} / \mathrm{capita})$, the trend $2011-2022$ would be more favorable in the new Member States $(+1.4 \%$ against $-1.6 \%$ in the old Member States). Pig meat is expected to remain the preferred meat in the EU with $40.8 \mathrm{~kg} /$ capita consumption in 2022, compared to 24.1 $\mathrm{kg}$ for poultry, $15.7 \mathrm{~kg}$ for beef/veal and less than $2.0 \mathrm{~kg}$ for sheep and goat meat. The net trade position of the EU is projected to deteriorate 
over the outlook period,driven by an increase in meat imports (of beef/veal, sheep and goat and poultry meats) and a parallel decline in exports of poultry. Aggregate meat imports would grow by 5.2\% (2022 vs. 2011) and exports would decline by $6.8 \%$, leaving the EU, nevertheless, a net exporter of pig and poultry meats in 2022 (European Commission, 2012).

\section{Options, challenges and potentials of poultry meat}

The meat industry is one of the most competitive international branches and is currently in its mature stage of development. Nutritional habits regarding meat and meat products have recently undergone some major changes. In the past, we have witnessed an intensive process of concentration and consolidation in the operating activities of the world poultry meat industry, as well as the poultry meat market being formed under the influence of shocks caused by the outbreak of the avian influenza (H5N1). The virus affected the entire European poultry meat industry and thus visibly marked the world trade with poultry meat in 2006.

The aim of this research is to present trends and projections on production and consumption of poultry meat, regardless the fluctuations in the previous year, and to enable better understanding of EU member state consumers' attitude and perception towards poultry meat. Taking into account that research has been conducted in the poultry sector in four countries EU member state generally and on consumer perceptions specifically, this results of the research could be used for planning further marketing activities.

In the continuation, the paper will focus on changes that have taken place on the European poultry meat market in the past few years, as well as on the indication of the development of the European poultry meat market in the coming years. The aim of this paper is also to enable better understanding of four countries EU member state consumers' attitude and perception towards poultry meat.

By 2022, poultry would be the only meat to record positive developments (Figure1) both in share and quantity consumed. Beef meat would maintain its share in total consumption at the 2011 level, but overall consumption would decline. Pig meat is expected to remain the most consumed meat in the EU with $40.8 \mathrm{~kg} / \mathrm{capita}$, which represents roughly half of total meat consumption; nevertheless the figure illustrates a declining trend both in terms of share and consumption. Sheep meat continues the declining trend in both per capita consumption and share (European Commission, 2012).

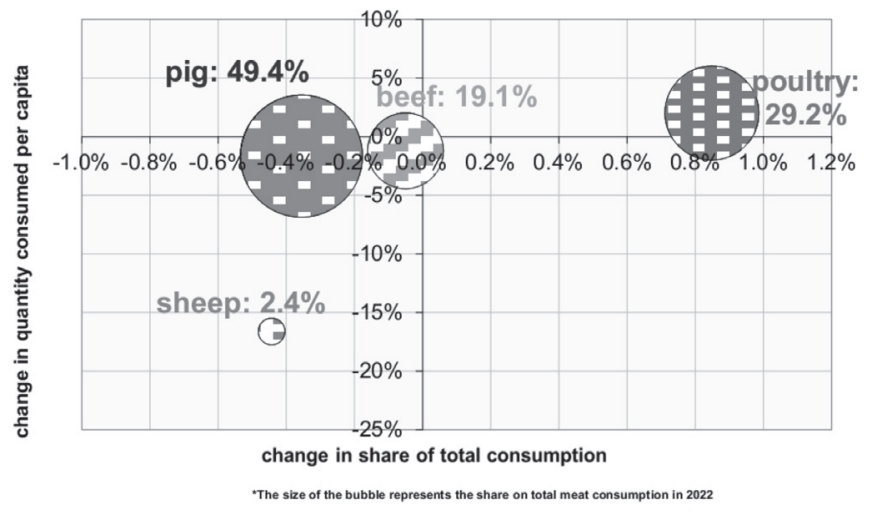

Figure 1 - EU meat consumption in 2022 compared to 2011 Source: European Commission (2012).

Higher EU demand for poultry in 2011 and its relative price competitiveness vis-à-vis other meat types triggered a $1.8 \%$ increase in production compared to 2010. This growth is expected to continue in the future, thus partially compensating the declining availability of other meats. Over the outlook period, poultry meat would be the only meat with increased levels of production $(+4.4 \%$ on aggregate compared to 2011), driven by higher global and domestic demand. The increasing production also reflects the capacity of poultry to adjust more rapidly to market shocks, both on the demand and the supply side. EU broiler prices have been at very high levels during 2012, peaking in September ( $€ 2040 / t$ ), when they were 16\% above the 2007-2011 average (European Commission, 2012). The EU meat sector is expected to be supported by strong demand on the world market,driven by improved economic conditions. In Europe, prospects of recovery in economic growth should leave consumers with more disposable income, allowing for a higher consumption of meat products. EU per capita meat consumption, which reached its lowest level for the past 11 years (64.7 kg retail eight) in 2013, is expected to recover from 2014 as more meat comes onto the market. In 2023, per capita consumption is expected to reach $66.1 \mathrm{~kg}$, similar to the 2011 level. Over the projection period, it is expected that poultry meat will remain the most dynamic product (thanks to its cheaper price, convenience and healthy image) and pork will remain Europe's favourite meat, while the consumption of beef and sheep meat is projected to drop both in absolute and relative terms (European Commission, 2013).

Overall, poultry meat imports recorded a 3\% decrease in the period between January and August 
2012 compared to the same period last year, with lower imports from Brazil (-6\%), the EU's main supplier, due to high prices and limited supply. On the other hand, imports from Thailand increased by $4 \%$. In July 2012, Thailand regained access to the EU market with frozen salted poultry meat (TRQ of 92000 tons) and, according to trade sources, is still building up capacity to fulfill the quota, although a higher uptake is expected in 2013. In contrast, for the same period, exports registered an increase of around $2 \%$, due to higher demand from African countries (exports to South Africa showing a 74\% increase), while exports to Russia and Asia decreased (-6\% and $-31 \%$ respectively) (European Commission, 2012).

Over the medium term, EU exports are expected to remain strong $(+3.2 \%$ in 2022 against 2011), due to growing world demand, especially in Asia, Africa and the Middle East. EU exports would be mainly concentrated on the lower-quality segment, i.e. the parts which do not find an outlet on the domestic market. Overall, imports of poultry meat into the EU would follow the same trend, but at a slower pace, increasing by $1.3 \%$, thus settling at 831000 tons by 2022. World consumption for poultry meat is projected to keep growing over the medium term $(+25 \%)$, a trend from which EU exports can benefit (Figure2) (European Commission, 2012).

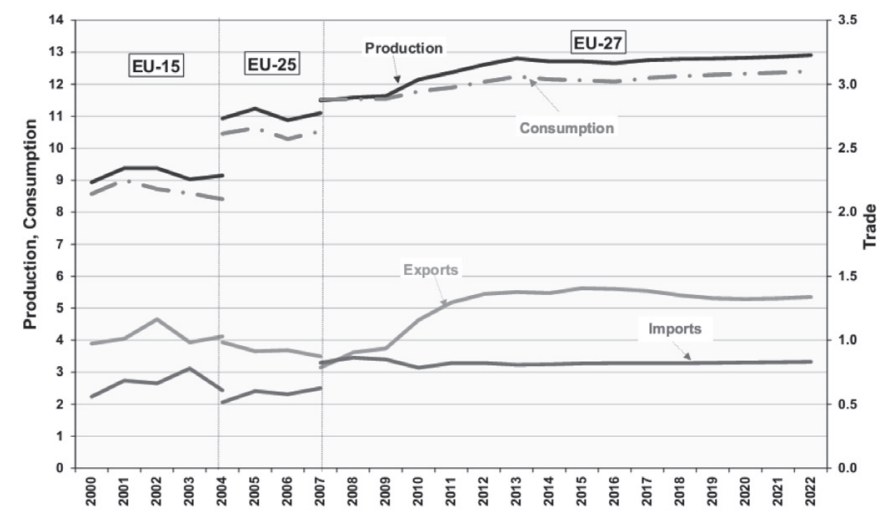

Figure 2 - EU poultry meat market developments (in million t) Source: European Commission, 2012.

EU poultry meat consumption is expected to increase by $4.3 \%$ on average and reach $24.1 \mathrm{~kg} / \mathrm{capita}$ by 2022 , mainly driven by the increasing volumes consumed in the EU-N12.Projections on production and consumption of poultry meat, regardless the fluctuations in the previous year, are predicting a growth trend for the EU market (European Commission, 2012).

Based on the results of the analyses and trends in the meat processing industry, it has been discovered that the poultry meat sector represents the market which is growing and is very dynamical. Poultry meat is one of the most favorite meat types. It is not only incredibly tasty, but it is also a food product that corresponds to the requirements of modern and balanced nutrition. In addition, it is quick and easy to prepare, healthy, safe, nourishing, and it offers a rich taste. The causes for the change in meat consumption have been a muchdebated issue in the agricultural economics literature (Becker et al., 2000, Grimshaw, 2013,Sismanoglou \& Tzimitra-Kalogianni, 2011;Vukasovič, 2009, 2010, 2011, 2014).

\section{METHODOLOGY}

\section{Research design and sample}

In order to investigate the buying habits and perceptions of poultry meat in four countries EU member state consumers, a quantitative research on the sample of $\mathrm{N}=2500$ poultry meat consumers was carried out in four countries EU member state. The research sample is representative according to the age (between 18 and 65 years), gender, region, and the population settlement type in the selected country. The method of internet interviews aided with the use of a structured questionnaire was used for interviewing.

The research took place from July to October 2013. In total, 2500 consumers were interviewed. The data was collected by internet in four different EU countries. The sampling method used was simple random sampling because it guarantees that every member of the population has a known and equal chance of being selected, with the resulting sample, no matter what the size, being a valid representation of the population (Schmidt \& Hollensen, 2006).

\section{Questionnaire}

The introduction letter, reminder, and draft questionnaire were developed for purpose of the research. The guidelines were used in order to give the questionnaire a good look and feel, and to ensure that respondents could progress quickly through it. All questionnaires carried a stamped number in order to be able to add factual consumers' data. The survey examined various factors and determinants that influence the attitudes, perceptions, consumption of poultry meat in four countries EU member state. The data were collected using a structured questionnaire administered on the field survey with the use of closed (questions with multiple choice answers) and open questions (questions that were not given the alternative answers). 
The questionnaire consisted of two main parts: the first part was related to general consumer behavior and attitudes toward poultry meat. The second part consisted of some socio-demographic questions. The consumer perception of poultry meat was measured by means of 5-point Likert scale, where 1 is the least safe and expensive meat and 5 represents the safest and the most expensive meat respectively. Analysis of quantitative data provided by mentioned questionnaire used the Statistical Package for Social Sciences (SPSS 17.0).

\section{RESULTS AND DISCUSSION}

\section{Buying habits and perceptions of poultry meat in four countries EU member state}

The data for analyzing the assortment of meat purchasing was collected by means of open-ended questions. Consumers consume mainly chicken $(97 \%)$ and turkey (83\%) and beef (55\%) and pork meat (47\%). Similar results about consumer's meat consumption were obtained in a study of Central and South East Europe consumers by Vukasovič (2011), in the study for Greece consumers by Sismanoglou \&Tzimitra-Kalogianni (2011) and in the study of Henchion et al (2014)."

About $95 \%$ of respondents claimed to buy poultry meat either "often" or "very often". Further, 9\% buy such meat "rarely", and 5\% of respondents either did not buy or they bought poultry meat very rarely (Figure3).
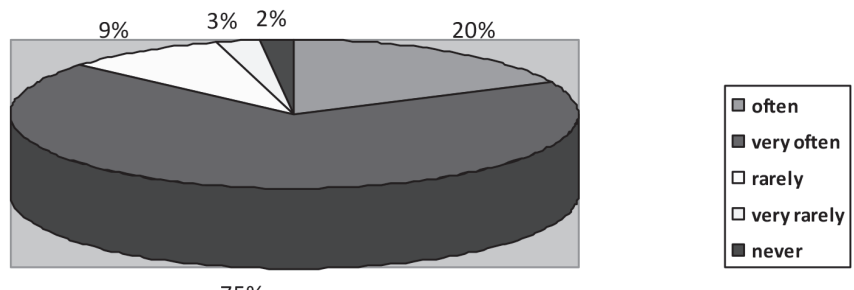

$75 \%$

Figure 3 - Frequency of the purchase of poultry meat

\section{Location of poultry meat purchase}

The main locations of poultry meat (chicken and turkey meat) purchase in four countries EU member state are most commonly hypermarkets (75\%) and supermarkets (62\%), followed by butcher's shops $(38 \%)$, directly from producers $(2 \%)$ and small selfgrocery $(2 \%)$. The results are shown in Figure4. Similar results about consumer's location of poultry meat purchase were obtained in a study of German consumers by Becker et al. 2000, Central and South
East Europe consumers by Vukasovič (2011) and in the study for Greece consumers by Sismanoglou \& Tzimitra-Kalogianni (2011).

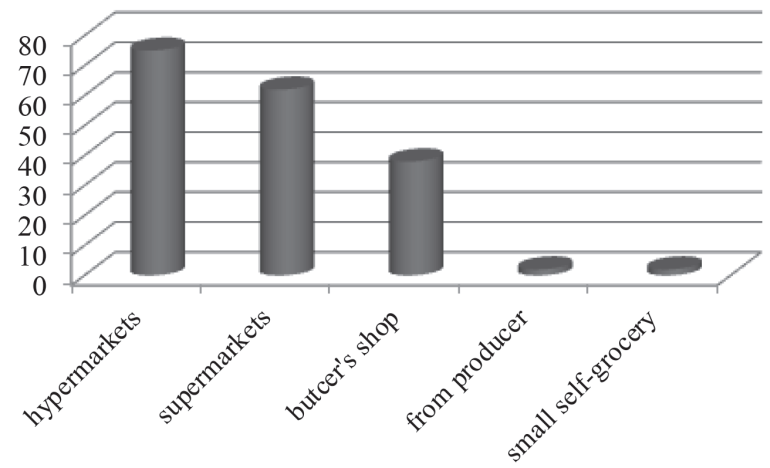

Figure 4 - Usual purchase places for poultry meat (\%)

In this part of the research, with face-to-face survey and with the method of semantic differential, in assembly of structured questionnaire, the stand points and the perception of consumers towards poultry meat the researcher has been researched. Characteristics of poultry meat, prepared in advance were in the questionnaire in order to help the consumers express their points of view toward the mentioned products. Respondents expressed their opinions by marking an answer in the proper spot. They were evaluating the characteristics that refer to poultry meat. The average evaluations of the recounted characteristics were calculated based on the acquired evaluations and by that an image of views of consumers toward poultry meat was determined. A research made in four countries EU member state shows that consumers perceive poultry meat as very healthy, safety, tasty, and of good quality (Figure 5).

Perception of poultry meat ( 1 - No, 5 - Yes)

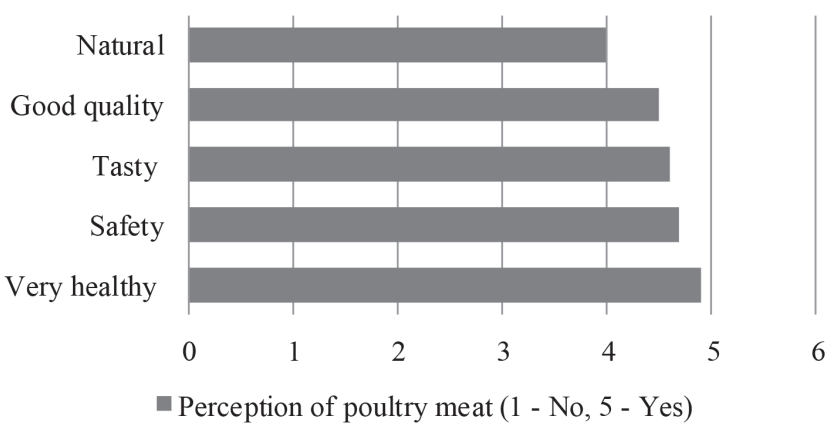

Figure $\mathbf{5}$ - Poultry meat perception

\section{Attitude toward the origin of meat}

Poultry meat is typically a distinctively generic product where a trade mark has no special importance when deciding whether to buy it or not. The trademark 
is built on factors of the consumer's way of thinking: the image of the trademark, its familiarity, familiarity of the name, perception of quality, fidelity, positive associations and other benefits (Aaker, 1991; Keller, 1998).

An important segment of the research was the one where we tried to determine the importance of fresh meat origin in the purchase-decision-making process. The results show that the $95 \%$ of persons interviewed decide to buy meat available from domestic sources. The percentage of persons interviewed who buy both meat of domestic and foreign origin is $18 \%$.We can thus confirm there is a significant tendency towards purchasing fresh poultry meat of domestic origin. Similar results about attitude toward the origin of meat were obtained in a study of Strašek (2011) and Vukasovič (2012). Also the results of these authors confirm the importance of meat origin in consumer decision-making process.

Meat industry is changing due to the changes in lifestyle, reshaped nutritional habits and needs of the consumers. The latter are more and more aware of the meaning of healthy and balanced diet. Nevertheless, we are concerned about what we eat. Health has become the most cherished value which means more health-friendly products. Therefore, the producers are developing products which offer ever more benefits to the consumers' health - they are promoting products with high impact on well-being. We, the consumers, have therefore begun to carefully read the declarations on products, giving special importance to the origin of products, which leads to a greater importance of packaging where the content and properties of products are combined. Trends like health, safe, less fat, without preservatives and additives, taste, are increasingly valued.

\section{CONCLUSIONS}

This study provides interesting insights for future developments of four countries EU member state meat market. One of the greatest challenges to developing successful marketing strategies in the food sector is gaining a better understanding of the diversity of consumer needs. These results are particularly useful for product marketing and future product development in the poultry meat market sector. This paper gives the latest insight into buying behavior and attitudes of four countries EU member state consumers. The results of the research could be used for planning further marketing activities in the poultry meat market sector.

\section{REFERENCES}

Aaker DA. Managing brand equity. New York: Free Press; 1991.

Becker T, Benner E. Glitsch K. Consumer perception of fresh meat quality in Germany. British Food Journal 2000;102(3):246-266.

European Commission. Prospects for agricultural markets and income in the EU 2012-2022. European Commission; 2012.

European Commission. Prospects for agricultural markets and income in the EU 2013-2023. European Commission; 2013.

Grimshaw KE. Consumer Oerception of beef, pork, lamb, chicken, and fish [thesis]. Texas: A \& M University; 2013. Available from: http: / /hdl .handle .net /1969.1/151396.

Henchion M, McCarthy M, Resconi VC, Troy D. Meat consumption: Trends and quality matters. Meat Science 2014;98(3): 561-568.

Keller KL. Conceptualizing, measuring and managing customer based brand equity. Journal of Marketing 1998;57(1):1-22

Sismanoglou A, Tzimitra-Kalogianni I. Consumer percpetion of poultry meat in Greece. World's Poultry Science Journal 2011;67(2):269-276

Schmidt, MJ, Hollensen S. Marketing research: An international approach. Harlow: Pearson Education; 2006.

Strašek R. The structural model of relations between country of origin and the perceived brand name value. World's Poultry Science Journal 2011;67(1):59-71.

Vukasovič T.Consumer perception of poultry meat and the importance of country of origin in a purchase making process. World's Poultry Science Journal 2009:65(1):65-74.

Vukasovič T. Buying - decision making process for poultry meat. British Food Journal 2010;112(2):125-139

Vukasovič T. The importance of national chicken meat origin in Central and South - Eastern Europe. World's Poultry Science Journal $2011 ; 67(2): 237-42$

Vukasovič T. Correlations between the country of origin (COO), marketing mix elements and the brand value. World's Poultry Science Journal 2012;68(4):627-636.

Vukasovič T. European meat market trends and consumer preference for poultry meat in buying decision making process. World's Poultry Science Journal 2014;70(2):289-302. 
